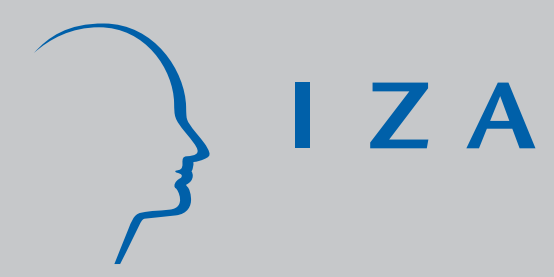

IZA DP No. 3258

\title{
On Pitchforks and Tomahawks
}

Michael Pflüger

J ens Südekum

December 2007 


\title{
On Pitchforks and Tomahawks
}

\author{
Michael Pflüger \\ University of Passau, \\ DIW Berlin and IZA
}

Jens Südekum

University of Duisburg-Essen

and IZA

\section{Discussion Paper No. 3258 \\ December 2007}

\author{
IZA \\ P.O. Box 7240 \\ 53072 Bonn \\ Germany \\ Phone: +49-228-3894-0 \\ Fax: +49-228-3894-180 \\ E-mail: iza@iza.org
}

\begin{abstract}
Any opinions expressed here are those of the author(s) and not those of the institute. Research disseminated by IZA may include views on policy, but the institute itself takes no institutional policy positions.

The Institute for the Study of Labor (IZA) in Bonn is a local and virtual international research center and a place of communication between science, politics and business. IZA is an independent nonprofit company supported by Deutsche Post World Net. The center is associated with the University of Bonn and offers a stimulating research environment through its research networks, research support, and visitors and doctoral programs. IZA engages in (i) original and internationally competitive research in all fields of labor economics, (ii) development of policy concepts, and (iii) dissemination of research results and concepts to the interested public.
\end{abstract}

IZA Discussion Papers often represent preliminary work and are circulated to encourage discussion. Citation of such a paper should account for its provisional character. A revised version may be available directly from the author. 
IZA Discussion Paper No. 3258

December 2007

\section{ABSTRACT}

\section{On Pitchforks and Tomahawks}

The core-periphery model by Krugman (1991) has two 'dramatic' implications: catastrophic agglomeration and locational hysteresis. We study this seminal model with CES instead of Cobb-Douglas upper tier preferences. This small generalization suffices to change these stark implications. For a wide range of parameters we find that the model exhibits instead a smooth and easily reversible transition from symmetry to agglomeration.

JEL Classification: F12, F15, F22, R12, R50

Keywords: core-periphery model, new economic geography, agglomeration, bifurcation pattern

Corresponding author:

Jens Südekum

University of Duisburg-Essen

Mercator School of Management

Lotharstraße 65

47057 Duisburg

Germany

E-mail: jens.suedekum@uni-due.de

\footnotetext{
* We thank Rainald Borck, Masahisa Fujita, Pierre Picard, Jacques-Francois Thisse and seminar participants in Halle and Savannah for very helpful comments and suggestions. Parts of this paper were written while Pflüger was visiting IZA. He gratefully acknowledges the hospitality of this institution.
} 


\section{Introduction}

Two of the most widely emphasized features of the seminal model of the 'new economic geography' (NEG), the core-periphery model by Krugman (1991), are catastrophic agglomeration and locational hysteresis. ${ }^{1}$ In the basic framework with two ex-ante identical regions, an equal division of economic activity is the only stable equilibrium for low levels of trade freeness. Once trade freeness has risen to a critical level, the so-called 'break point', all mobile activity agglomerates 'catastrophically' and fully in one region. Yet, a reversal of the trade integration need not restore symmetry, because the core-periphery pattern is stable up to a 'sustain point' which lies at a strictly lower level of trade freeness than the break point. Technically speaking, the core-periphery model exhibits a 'tomahawk bifurcation' as shown in figure $1 \mathrm{a}^{2}$ This location pattern and its implications (lock-in effects, 'history matters') have attracted huge attention in the subsequent theoretical and empirical literature, and are at least partly responsible for the major appeal of the NEG.

Subsequent research has shown that the tomahawk pattern is not a robust feature of NEG models in general. For example, when elements of heterogeneity (Tabuchi and Thisse 2002), mobility costs (Ludema and Wooton 1999) or urban costs (Helpman 1998; Tabuchi 1998) are added, or when quasi-linear preferences (Ottaviano et al. 2002; Pflüger 2004) or decreasing returns to labor in the outside sector (Puga 1999) are assumed, the hysteresis feature vanishes and the agglomeration process becomes smooth. ${ }^{3}$

In this note we show - quite strikingly - that even a more minor change of assumptions suffices to change the stark features of the core-periphery model. We retain the homotheticity of preferences, but assume a CES- rather than a Cobb-Douglas upper tier utility function. Using this slightly more general setup we find that trade integration indeed triggers

\footnotetext{
${ }^{1}$ Fujita et al. (1999), Baldwin et al. (2003) and Ottaviano and Thisse (2004) provide overviews of the NEG.

2 The tomahawk bifurcation is sometimes also labelled 'subcritical pitchfork bifurcation'. We avoid this terminology in order to clearly distinguish it from the (supercritical) 'pitchfork bifurcation'. For an introduction to bifurcations and their formal definitions, see Fujita et al. (1999) or Grandmont (1988).

${ }^{3}$ Unlike the other referenced works, the model by Ottaviano et al. (2002) has catastrophic agglomeration but no hysteresis. On this point, see also Pflüger and Südekum (2008).
} 
agglomeration due to endogenous market size effects, as in the original model. However, this process is not necessarily catastrophic and need not feature locational hysteresis. Subject to specific parameter constellations of the upper-tier substitution elasticity and the substitution elasticity across the single manufacturing varieties, there can be a smooth and easily reversible transition from symmetry to agglomeration (a 'pitchfork bifurcation' as in fig. 1b).

\section{Figure 1a) tomahawk bifurcation}

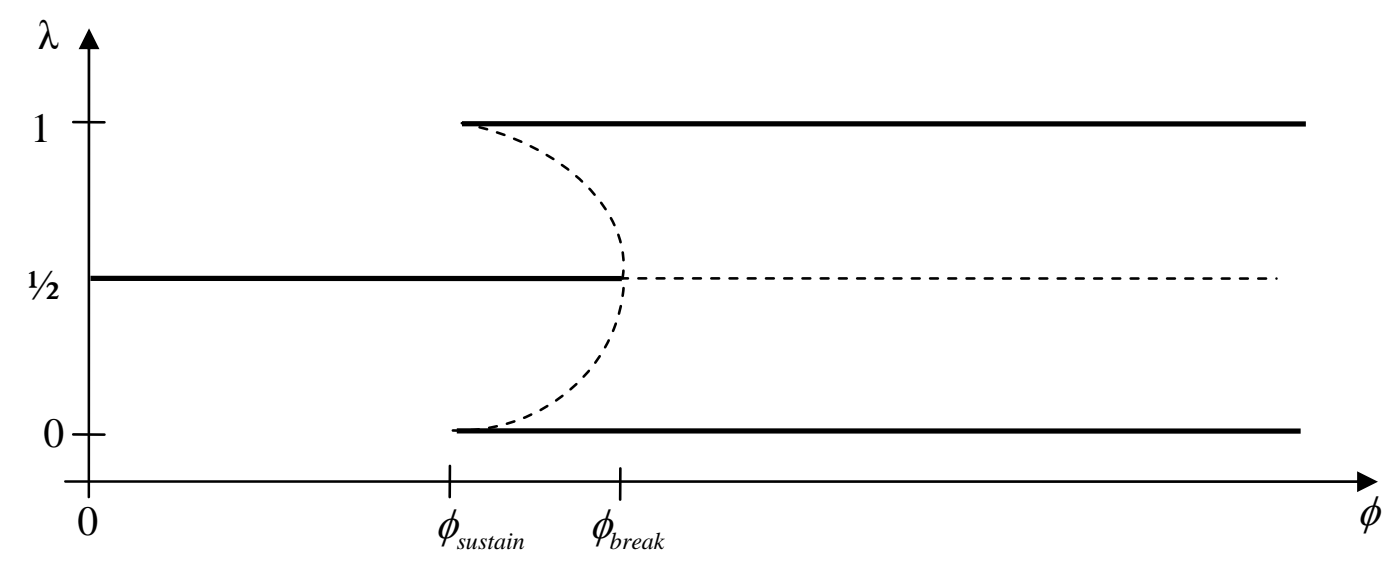

\section{Figure 1b) pitchfork bifurcation}

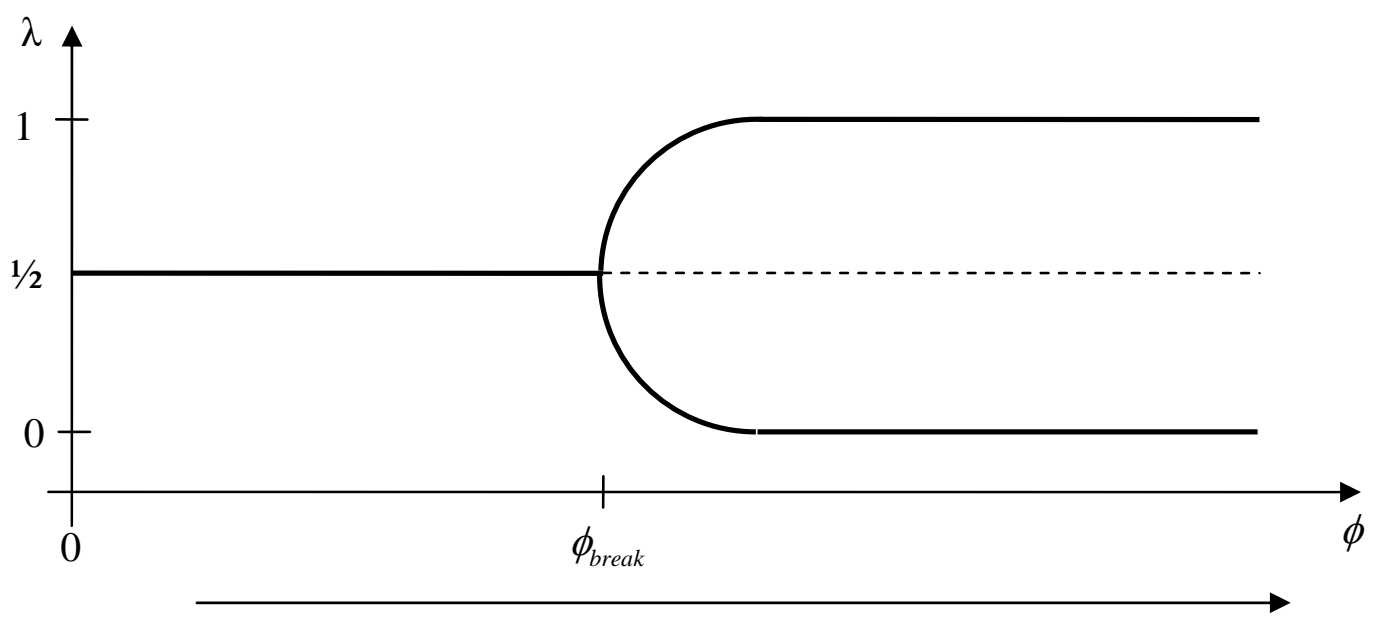

Our analysis suggests that some of the specific 'dramatic' features of the seminal NEG-model hinge crucially on the functional form of the assumed Cobb-Douglas preferences. Empirical and policy oriented work should therefore treat these particular features very cautiously when drawing conclusions from the NEG. 
The rest of this paper is organized as follows. The model is presented in the next section. Section 3 analyzes symmetry breaking and the bifurcation pattern, and section 4 concludes.

\section{The model}

To make our points in the simplest way, we build on the analytically tractable version of the core-periphery model developed by Forslid and Ottaviano (2003). ${ }^{4}$ The economy is composed of two (ex-ante) identical regions $r=1,2$, two industries $A$ (agriculture) and $M$ (manufacturing), and two types of individuals. Skilled workers are mobile across regions. Their total endowment is normalized to one, and the share $\lambda_{r}$ is located in region $r$. Unskilled workers are geographically immobile and equally distributed across regions. The parameter $\rho$ denotes the endowment of either region with unskilled workers. In the perfectly competitive A-sector one unit of the homogeneous output is produced with one unit of unskilled labor. The monopolistically competitive sector produces a large variety of differentiated goods. Each variety $i$ is produced by a single firm. It takes one unit of skilled labor to produce at all. Then, one unit of output is produced with $c$ units of unskilled labor. ${ }^{5}$ Cross-border transport of $M$-varieties is subject to iceberg costs $\tau>1$. The $A$-good is traded without costs. It is chosen as the numéraire. Its price and, therefore, the wage of unskilled workers is unity in both industries and locations, $p_{r}^{A}=w_{r}^{U}=1$. Due to the fixed input requirement the overall number of manufacturing firms/varieties in either region is determined by the supply of skilled labor. Competition for skilled workers implies that their wage absorbs the operating surplus of firms, implying zero profits in the long-run equilibrium.

\footnotetext{
${ }^{4}$ It is well known that the original Krugman-model can only be solved by means of numerical simulations (see Fujita et al., 1999). We have also analyzed a generalized version of that model with CES- instead of CobbDouglas upper tier preferences. Our numerical results are qualitatively identical to those reported in this paper. Hence, we decided to focus on the analytically tractable 'footloose entrepreneur' model by Forslid and Ottaviano (2003). More detailed results on the original Krugman-framework are available upon request from the authors.

${ }^{5}$ In the core-periphery model of Krugman, the two types of labor are sector specific, and skilled labor enters both in the fixed and variable costs of manufacturing goods. A more detailed comparison of Krugman (1991) and Forslid and Ottaviano (2003) can be found in Baldwin et al. (2003).
} 
The only difference between our model and Forslid and Ottaviano (2003) is the specification of individual preferences. We assume that individuals have a CES- rather than a CobbDouglas upper tier utility function. In region $r$ preferences are given by:

$$
U_{r}\left(A_{r}, M_{r}\right)=\left[A_{r}^{\frac{\varepsilon-1}{\varepsilon}}+M_{r}^{\frac{\varepsilon-1}{\varepsilon}}\right]^{\frac{\varepsilon}{\varepsilon-1}}, \quad M_{r}=\left(\int_{0}^{n_{r}} m_{r r}(i)^{\frac{\sigma-1}{\sigma}} d i+\int_{n_{r}}^{n_{r}+n_{s}} m_{s r}(i)^{\frac{\sigma-1}{\sigma}} d i\right)^{\frac{\sigma}{\sigma-1}}
$$

The elasticity of substitution between the bundle of manufactures and the agricultural good is given by $\varepsilon$. The total mass of varieties in the $M$-sector is $n=n_{r}+n_{s}$ where $s=1,2$ and $s \neq r$. Region $r$ 's consumption of varieties produced in the own region and in the other region is denoted by $m_{r r}(i)$ and $m_{s r}(i)$, respectively. $\sigma$ expresses the elasticity of substitution between any two manufacturing varieties. Denoting aggregate income in region $\mathrm{r}$ by $Y_{r}$ and producer prices by $p_{r}(i)$ and $p_{s}(i)$, the budget constraint can be written as:

$$
Y_{r}=A_{r}+\int_{0}^{n_{r}} p_{r}(i) m_{r r}(i) d i+\int_{n_{r}}^{n_{r}+n_{s}} \tau p_{s}(i) m_{s r}(i) d i
$$

The following demand functions then follow from standard utility maximization:

$$
\begin{array}{cc}
A_{r}=\left(G_{r}\right)^{\varepsilon-1} Y_{r} & M_{r}=\left(G_{r}^{M}\right)^{-\varepsilon}\left(G_{r}\right)^{\varepsilon-1} Y_{r} \\
m_{r r}(i)=p_{r}(i)^{-\sigma}\left(G_{r}^{M}\right)^{\sigma-\varepsilon}\left(G_{r}\right)^{\varepsilon-1} Y_{r} & m_{s r}(i)=\left(\tau p_{s}(i)\right)^{-\sigma}\left(G_{r}^{M}\right)^{\sigma-\varepsilon}\left(G_{r}\right)^{\varepsilon-1} Y_{r}
\end{array}
$$

where region $r$ 's overall price index $G_{r}$ and the standard CES-price index for manufacturing varieties $G_{r}^{M}$ are given by

$$
G_{r}=\left[1+\left(G_{r}^{M}\right)^{1-\varepsilon}\right]^{\frac{1}{1-\varepsilon}} \quad G_{r}^{M}=\left[n_{r} p_{r}^{1-\sigma}+n_{s}\left(\tau p_{s}\right)^{1-\sigma}\right]^{\frac{1}{1-\sigma}}
$$

In this paper we shall focus on the economically plausible 'normal case' where $\sigma>\varepsilon \geq 1$, i.e., the elasticity of substitution within the group of manufactures is higher than the one 
between manufactures and the agricultural good. Hence, by (4), the demand for a specific variety rises in response to an increase in the general manufacturing price level $G_{r}^{M}{ }^{6}$

Region $r$ 's aggregate income $Y_{r}$ consists of the wage incomes accruing to the unskilled $\left(w_{r}^{U}=1\right)$ and the skilled workers $\left(w_{r}\right)$,

$$
Y_{r}=\rho+w_{r} \lambda_{r}
$$

Taking into account that part of demand is indirect, caused by transport losses, total output of any variety produced is given by

$$
q_{r}(i)=m_{r r}(i)+\tau \cdot m_{r s}(i)
$$

Mill pricing applies in this Dixit-Stiglitz model of monopolistic competition. With mill price $p_{r}(i)=\bar{p}$, firm's profits are given by $\pi_{r}(i)=\left(p_{r}(i)-c\right) q_{r}(i)-w_{r}^{M}$. Maximizing profits and using (6) and (4) yields mill prices $\bar{p}=\sigma \cdot c /(\sigma-1)$. Choosing units such that $c=(\sigma-1) / \sigma$, we can henceforth use $\bar{p}=1$. In long-run equilibrium all operating profits accrue to skilled labor, hence the wage for skilled workers in region $r$ is given by

$$
w_{r}=q_{r}(i) / \sigma
$$

and the number of firms in either region is determined by the supply of skilled workers

$$
n_{r}=\lambda_{r}
$$

It is the hallmark of the Forslid-Ottaviano-model that the wages for the skilled workers in the two regions can be determined analytically for a given distribution of skilled labor $\lambda_{r}$. These properties remain valid in our generalized model with CES preferences. After tedious yet straightforward computations the following solution for the wages $w_{r}$ can be derived by using (4), (5), (6), (8) and (9)

\footnotetext{
${ }^{6}$ Helpman (1990) discusses this assumption in the context of his analysis of tariffs under monopolistic competition.
} 


$$
w_{r}=\frac{\rho \cdot\left[\sigma\left(\phi \cdot b_{r}+b_{s}\right)-\left(1-\lambda_{r}\right)\left(1-\phi^{2}\right)\right]}{\left[\left(\lambda_{r}-\sigma \cdot b_{r}\right)\left(1-\lambda_{r}-\sigma \cdot b_{s}\right)-\lambda_{r}\left(1-\lambda_{r}\right) \phi^{2}\right]}
$$

where $b_{r} \equiv\left(G_{r}\right)^{1-\varepsilon}\left(G_{r}^{M}\right)^{\varepsilon-\sigma}$ and $\phi \equiv \tau^{1-\sigma} \in[0,1]$ denotes the usual measure of trade freeness. Using (10), all other endogenous variables can readily be inferred for a given spatial distribution $\lambda_{r}$. In particular, we can derive an explicit expression for the indirect utility level of a mobile skilled worker in region $r$. Associated with (1) is an indirect utility function of the form $V_{r}=w_{r} / G_{r}$, whose value for given $\lambda_{r}$ then follows directly from (10) and (5).

\section{Symmetry breaking and bifurcation pattern}

Symmetry breaking. In the long-run, the skilled workers move in response to indirect utility differences across regions. As regions are ex-ante identical, symmetry $\left(\lambda_{r}=1 / 2\right)$ is always an equilibrium. However, since the model features the usual agglomeration forces, a supply and a demand linkage, the symmetric equilibrium is not necessarily stable. The supply linkage expresses the fact that a relocation of skilled labor to region $r$ lowers the price level through trade cost savings and increases the utility of skilled workers in $r$. Moreover, the market size in $r$ expands, thereby increasing the operating profits of firms and hence the wage and indirect utility of skilled workers in that region (demand linkage). Counteracting these agglomeration forces is the increasing product market competition that is accompanied by a shift of skilled labor to $r$.

The balance of these forces depends on the level of trade freeness $\phi$. The critical level $\phi_{b}$ at which the symmetric equilibrium then turns unstable is determined by the condition $d\left(V_{r}-V_{s}\right) / d \lambda_{r}=0$ at $\lambda_{r}=1 / 2$, i.e., by equating the first derivative of the utility differential at the symmetric equilibrium to zero. Since the present model is a member of the class of 'footloose entrepreneur' models, it is convenient to apply the general approach developed by 
Pflüger and Südekum (2008) to solve for the break point of this model (see appendix A for details). This yields the following implicit function

$$
F(\phi, \sigma, \varepsilon)=\frac{1}{1+z}-\left[\frac{(\sigma-1)[(1+\phi)-\sigma(1-\phi)]-\sigma(\sigma-\varepsilon)(1-\phi) z}{(1-\phi)-\sigma(1+\phi)(1+z)}\right]=0
$$

where $z \equiv 2^{\frac{\varepsilon-1}{\sigma-1}}(1+\phi)^{\frac{1-\varepsilon}{\sigma-1}}$. Even though it is not possible to solve (11) explicitly for the break point $\phi_{b}(\sigma, \varepsilon)$, we can use this implicit function to establish a number of insights. In particular, since (11) is composed of three parameters only, we can visualize the solution $\phi_{b}(\sigma, \varepsilon)$ for the break point condition in three-dimensional space for the full admissible parameter range of $\sigma$ and $\varepsilon .^{7}$ In figure 2 we provide an easier interpretable two-dimensional cut through this three-dimensional surface. This yields curves $\phi_{b}(\varepsilon ; \bar{\sigma})$ where $\sigma$ is fixed at some $\bar{\sigma}$.

\section{Figure 2: Symmetry breaking levels of trade-freeness}

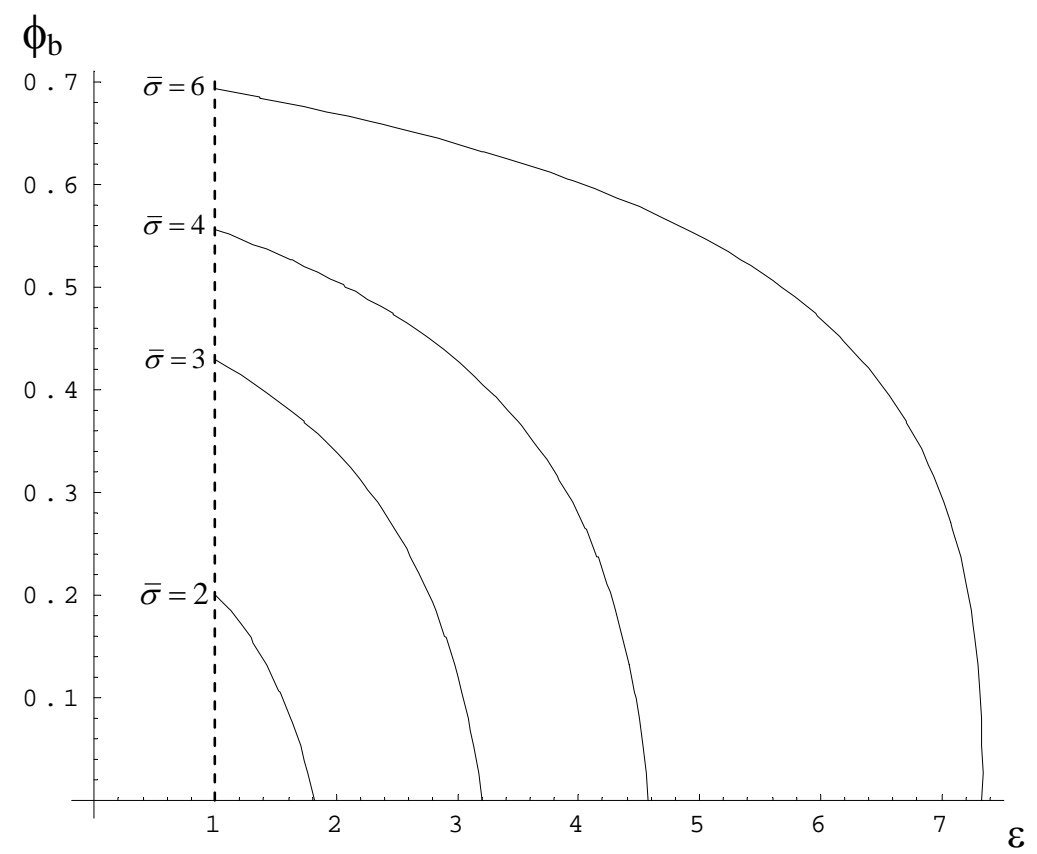

Note: The curves depict the break-points $\phi_{b}(\varepsilon ; \bar{\sigma})$. Larger values of $\bar{\sigma}$ lead to outward shifts of the curves

\footnotetext{
${ }^{7}$ The endowment of unskilled labor $\rho$ does not affect the break point. This is due to the fact that $\rho$ enters the wage equation (10) in multiplicative form and therefore does not affect relative regional wages.
} 
Successively higher values of $\bar{\sigma}$ shift these curves further away from the origin. Figure 2, thus, reveals that the symmetry breaking level of trade freeness is increasing in $\sigma$. This corresponds to the usual result that the break point increases when the single manufacturing varieties become better substitutes (Fujita et al. 1999). The novel parameter in our analysis is the upper-tier substitution elasticity $\varepsilon$. Figure 2 suggests that the break point $\phi_{b}$ is unambiguously decreasing in $\varepsilon$. In fact, making use of the parameter restriction $\sigma>\varepsilon \geq 1$, we are able to prove the following result analytically:

Proposition 1: For the core-periphery model with CES upper tier preferences the following result holds: Assuming $\sigma>\varepsilon \geq 1$ the break point $\phi_{b}(\sigma, \varepsilon)$ is unambiguously decreasing in the upper tier substitution elasticity $\left(d \phi_{b} / d \varepsilon<0\right)$.

Proof: See Appendix A

What is the economic intuition for this result? A priori our expectation was that it should be understood in terms of the demand linkage: with CES preferences and $\varepsilon>1$, the fall in prices that is induced by trade integration should increase the expenditure share devoted to manufactured goods, thus, strengthening the demand linkage. This should then lead to agglomeration over a larger range of $\phi$ the higher $\varepsilon$ is. ${ }^{8}$ However, a decomposition of the break point condition into the parts attributable to the linkages and the competition effect shows that matters are more complicated. The analytical formulae provided in appendix B show that each of the three location forces is in a complex way affected by $\varepsilon$. Simulations reveal that none of the three forces exhibits unambiguous comparative statics with respect to

\footnotetext{
${ }^{8}$ This intuition is shaped by the usual textbook logic, and it was reinforced by our reading of the analysis of the home market effect by Yu (2005), which is one key agglomeration force in NEG models. Yu finds that the existence of the home market effect is very much dependent on whether the elasticitiy of substitution is greater or smaller than one. However, it must be noted that his analysis is not directly applicable to our setting, since he considers trade costs for all goods (the agricultural good as well as manufacturing) whereas we assume that the agricultural good is traded without costs. Davis (1998) shows that it matters for the home market effect if agricultural trade is costly even if the upper-tier preferences are of the (usual) Cobb-Douglas type.
} 
$\varepsilon$. Since the break point reflects the interaction of all three intricate forces, it is obvious that no simple intuition can be provided for why the break point is decreasing in $\varepsilon$. We have only proved in proposition 1 that this is actually so.

The bifurcation pattern. The detailed study of symmetry breaking has paved the way for the analysis of the bifurcation pattern, which is the main focus of our paper. The type of the bifurcation that unfolds at the break point can be addressed by evaluating the sign of the third derivative of the utility differential for mobile skilled workers (see Grandmont 1988 on this). If the third derivative, evaluated at the symmetrical equilibrium $\lambda_{r}=1 / 2$ and at the symmetry breaking level of trade freeness $\phi=\phi_{b}$, is positive, we have the catastrophic tomahawk bifurcation. If it is negative the smooth pitchfork bifurcation follows,

$$
\left.\tilde{V}_{(3)} \equiv \frac{d^{3}\left(V_{r}-V_{s}\right)}{d \lambda_{r}^{3}}\right|_{\lambda_{r}=1 / 2, \phi=\phi_{b}}, \quad \begin{aligned}
\tilde{V}_{(3)}>0 & \rightarrow \text { tomahawk-bifurcation } \\
\tilde{V}_{(3)}<0 & \rightarrow \text { pitchfork-bifurcation }
\end{aligned}
$$

Owing to the fact that no closed-form solution for the break point $\phi_{b}$ can be provided we cannot solve explicitly for this third derivative $\tilde{V}_{(3)}$. However, we can proceed conveniently with a numerical approach. Since the break point $\phi_{b}(\sigma, \varepsilon)$ is determined by two parameters only, we can numerically solve $\phi_{b}(\sigma, \varepsilon)$ for different values of $\sigma$ and $\varepsilon$, plug the solution into (12) and obtain the corresponding value of $\tilde{V}_{(3)}\left(\sigma, \varepsilon, \phi_{b}(\sigma, \varepsilon)\right)$. Repeating this procedure for arbitrary many parameter constellations $\{\sigma, \varepsilon\}$ we can cover - in principle - the complete admissible parameter range where a break point $\phi_{b} \in[0,1]$ exists, so that our numerical results are exhaustive and not merely a collection of selective examples (see appendix $\mathrm{C}$ for more details). The essence of this analysis can be represented graphically as in figure 3. 
In this two-dimensional figure we represent the sign of $\tilde{V}_{(3)}$ for different $\{\sigma, \varepsilon\}-$ constellations. The value of $\sigma$ increases along the vertical, and the value of $\varepsilon$ along the horizontal axis. Our assumption that $\sigma>\varepsilon \geq 1$ implies that we focus on the area below the main diagonal in figure 3. The light grey area characterizes the set of parameters where $\tilde{V}_{(3)}>0$, i.e., where the model exhibits the catastrophic tomahawk bifurcation. The dark area characterizes the parameter range where a smooth pitchfork obtains $\left(\tilde{V}_{(3)}<0\right)$. Note that the standard core-periphery model with Cobb-Douglas preferences is represented here through the left borderline of the box (where $\varepsilon=1$ with varying $\sigma$ ), where in fact the tomahawk shape of the bifurcation pattern is observed.

\section{Figure 3: Third derivative of indirect utility differential at symmetry breaking levels of trade freeness}

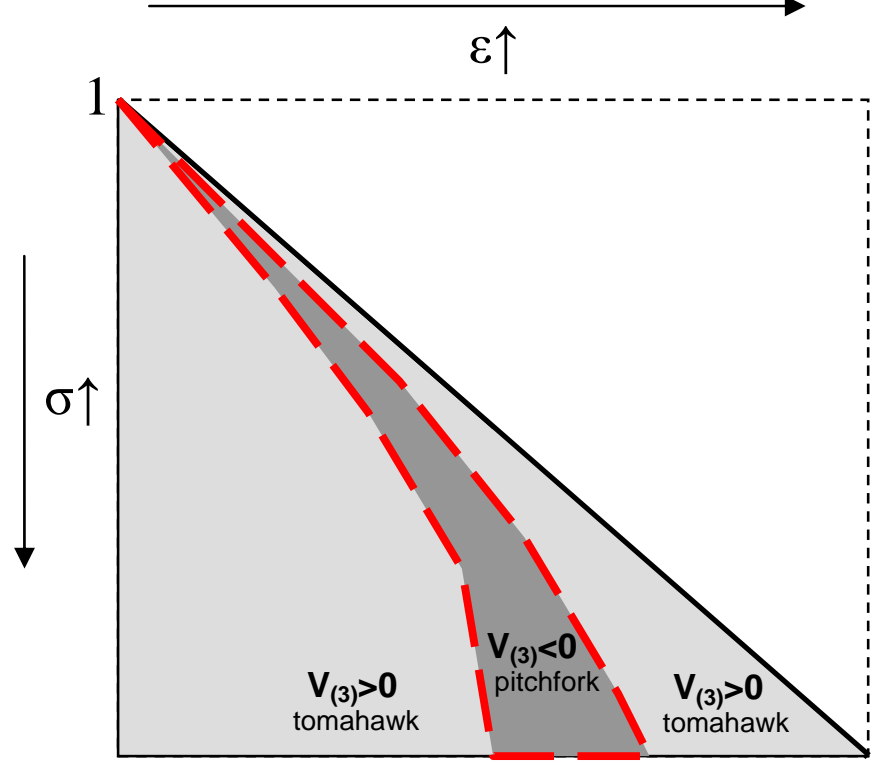

Note: See also appendix $\mathrm{C}$ for an example of the numerical computations underlying this figure

Yet, for a wide range of parameters where the upper tier substitution elasticity $\varepsilon$ exceeds unity, we find that the model instead exhibits the smooth pitchfork pattern. This range of $\varepsilon$ values for which the model delivers a pitchfork tends to increase at larger values of $\sigma$, and 
this location pattern requires that $\varepsilon$ is neither to close, nor too far away from the value of $\sigma$. Summing up, we have the following main result:

Proposition 2: For the core-periphery model with CES upper tier preferences the following result holds: Assuming $\sigma>\varepsilon \geq 1$, there exists a range of parameter constellations $\{\sigma, \varepsilon\}$ for which the model exhibits a pitchfork bifurcation rather than a tomahawk bifurcation.

\section{Conclusion}

In this note we show that there need not be catastrophic agglomeration with hysteresis in the standard model of the new economic geography, once the upper-tier utility function is slightly generalized to a CES-function. We identify the full set of parameters where instead a smooth pitchfork bifurcation obtains.

The more general message that comes out of our analysis is that, from a theoretical point of view, the dramatic implications of the Krugman-model are the exception rather than the rule. Other contributions from the NEG-literature (references above) have already shown that the tomahawk pattern is not robust. The main point of this paper is to show that even a minimal deviation from the original specification of preferences yields the same insight.

A smooth pitchfork bifurcation appears to be more plausible from the point of view of descriptive realism, and serious empirical work seems to confirm this view (see e.g. Head and Mayer 2004). For policymakers this implies that NEG-theory provides no robust rationale as to why small policy changes should have catastrophic consequences. 


\section{References}

Baldwin, R., R. Forslid, P. Martin, G. Ottaviano and F. Robert-Nicoud, 2003, Economic geography and public policy, Princeton: Princeton University Press.

Davis, D., 1998, The home market, trade, and industrial structure, American Economic Review 88:5, 1264-1276

Forslid, R. and Ottaviano, G., 2003, An analytically solvable core-periphery model, Journal of Economic Geography 3, 229 - 240.

Fujita, M., P. Krugman and A.J. Venables, 1999, The spatial economy. Cities, regions, and international trade, Cambridge (Mass.): MIT Press.

Grandmont, J.M., 1988, Nonlinear Difference Equations, Bifurcations and Chaos: An Introduction, Lecture Notes No. 5, May, IMSSS-Economics Lecture Notes Series, Institute for Mathematical Studies in the Social Sciences, Stanford, CA.

Head, K. und Th. Mayer, 20004, The empirics of agglomeration and trade, in: V. Henderson und J.F. Thisse (eds.), Handbook of regional and urban economics, vol. IV, North Holland Amsterdam, 2609-2696

Helpman, E., 1990, Monopolistic competition in trade theory, Special Papers in International Economics no. 16, Department of Economics, Princeton, New Jersey

Helpman, E., 1998, The size of regions, In: D. Pines, E. Sadka, I. Zilcha (eds.), Topics in public economics. Theoretical and empirical analysis, Cambridge University Press: 33-54

Krugman. P., 1991, Increasing returns and economic geography, Journal of Political Economy 99, 483-499.

Ludema, R. D. und I. Wooton, 1999, Regional integration, trade and migration: are demand linkages relevant in Europe? In: R. Faini, J. De Melo und K.F. Zimmermann (eds.), Migration. The controversies and the evidence, CEPR and Cambridge University Press, 51-75

Neary, J.P., 2001, Of hype and hyperbola: introducing the new economic geography, Journal of Economic Literature 39, 536-561.

Ottaviano, G.I.P., J.-F. Thisse, 2004, Agglomeration and economic geography, in: J.-F. Thisse, J.V. Henderson (eds.), Handbook of Regional and Urban Economics: Cities and Geography, Volume 4, Elsevier, 2563-2608.

Ottaviano, G.I.P., T. Tabuchi and J.-F. Thisse, 2002, Agglomeration and trade revisited, International Economic Review 43, 409-435.

Pflüger, M., 2004, A simple, analytically solvable, Chamberlinian agglomeration model, Regional Science and Urban Economics 34, 565-573.

Pflüger, M., J. Südekum, 2008, A synthesis of footloose-entrepreneur new economic geography models: When is agglomeration smooth and easily reversible? forthcoming in: Journal of Economic Geography

Puga, D., 1999, The rise and fall of regional inequalities, European Economic Review 43, 303-334.

Tabuchi, T., J.-F.Thisse, Taste heterogeneity, labor mobility and economic geography, Journal of Development Economics 69 (2002) 155-177.

Tabuchi, T., Urban agglomeration and dispersion: A synthesis of Alonso and Krugman, Journal of Urban Economics 44 (1998), 333-351

Yu, Z., 2005, Trade, market size, and industrial structure: revisiting the home-market effect, Canadian Journal of Economics 38, 255-272 


\section{Appendix A: Break point condition and proof of proposition 1}

In Pflüger and Südekum (2008), who analyze footloose entrepreneur models with a general indirect utility function, it is shown that the symmetry breaking level of trade freeness $\phi_{b}$ lies where the following condition is satisfied at the symmetrical configuration $\left(\lambda_{r}=1 / 2\right)$ :

$$
-\left[\frac{\partial V_{r} / \partial G_{r}}{\partial V_{r} / \partial w_{r}}\right]=\frac{d w_{r} / d \lambda_{r}}{d G_{r} / d \lambda_{r}} \Leftrightarrow \phi=\phi_{b}
$$

Noting that $-\left(\partial V_{r} / \partial G_{r}\right) /\left(\partial V_{r} / \partial w_{r}^{M}\right)=w_{r} / G_{r}$ in the present case (since $V_{r}=w_{r} / G_{r}$ ), we can rewrite the break point condition as $\left[\left(1 / w_{r}\right) \cdot\left(d w_{r} / d \lambda_{r}\right)-\left(1 / G_{r}\right) \cdot\left(d G_{r} / d \lambda_{r}\right)\right]=0$. Using (5) and (10) these components at the symmetrical configuration are given by

$$
\begin{aligned}
& \left(1 / w_{r}\right) \cdot\left(d w_{r} / d \lambda_{r}\right)=\frac{2\left((1-\phi)(1+\phi-\sigma(1-\phi))-\frac{\sigma(\sigma-\varepsilon)}{\sigma-1} \cdot z(1-\phi)^{2}\right)}{\sigma(1+\phi)^{2}(1+z)+\phi^{2}-1} \\
& \left(1 / G_{r}\right) \cdot\left(d G_{r} / d \lambda_{r}\right)=-\frac{2(1-\phi) \quad \text { where } z \equiv 2^{\frac{\varepsilon-1}{\sigma-1}}(1+\phi)^{\frac{1-\varepsilon}{\sigma-1}}}{(\sigma-1)(1+\phi)(1+z)}
\end{aligned}
$$

Applying the above break point condition and rearranging terms yields the implicit function (11) in the main text.

\section{Proof of proposition 1}

This implicit function $F(\sigma, \varepsilon, \phi)=0$ in (11) can be rewritten in the following form

$$
\sigma(3+\phi-\sigma(1-\phi))-\phi-1=(1-\phi) \sigma(\sigma-\varepsilon) z+\frac{1-\phi}{1+z}
$$

The LHS of this equation does not depend on $\varepsilon$, whereas the RHS depends on $\varepsilon$ (both directly and indirectly via the term $z$ ). It can be shown that the LHS of (16) is linearly increasing in $\phi$, whereas the RHS of (16) is monotonously decreasing in $\phi$ provided our parameter restriction $\sigma>\varepsilon \geq 1$. Hence, whenever a break point exists (where LHS=RHS) it must be unique. Furthermore, the RHS is also monotonously decreasing in $\varepsilon$ provided $\sigma>\varepsilon \geq 1$. The downward sloping curve (RHS) shifts downwards as $\varepsilon$ increases and, hence, the break point $\phi_{b}$ that solves (16) must be decreasing in $\varepsilon$. This proves proposition 1 .

Full details about this derivation including all derivatives of the RHS of (16) can be found in a web supplement to this paper, which is available under http://www.uni-due.de/js 


\section{Appendix B: Decomposition of locational forces}

For the determination of the breakpoint, the response of the utility differential with respect to a small change in $\lambda_{r}$ taken at the symmetric equilibrium $\lambda_{r}=1 / 2$ is needed. This utility response can be decomposed into the three analytical effects below and have to be evaluated at the values of the endogenous variables in the symmetric equilibrium listed below.

supply linkage (sl)

$$
\mathrm{sl}=\left.\frac{d\left(\frac{w_{r}}{G_{r}}-\frac{w_{s}}{G_{s}}\right)}{d \lambda_{r}}\right|_{\substack{\lambda_{r}=1 / 2 ; \\ w_{r}^{M} \cdot w_{s}^{M} \text { given }}}=-2 \frac{w_{r}}{G_{r}^{2}} \frac{d G_{r}}{d \lambda_{r}}
$$

demand linkage (dl)

$$
\mathrm{dl}=\left.\frac{d\left(\frac{w_{r}}{G_{r}}-\frac{w_{s}}{G_{s}}\right)}{d \lambda_{r}}\right|_{\substack{\lambda_{r}=1 / 2 ; \\ G_{r}, G_{s} \text { given in denominator } \\ \text { only } Y_{r}, Y_{s}{\text { variable in } m_{r r}, m_{s r}}}}=\frac{4 w_{r}(1-\phi)}{G_{r}}\left[\frac{\left(G_{r}^{M}\right)^{\sigma-\varepsilon}\left(G_{r}\right)^{\varepsilon-1}}{2 \sigma-(1-\phi)\left(G_{r}^{M}\right)^{\sigma-\varepsilon}\left(G_{r}\right)^{\varepsilon-1}}\right]
$$

competition effect (ce)

$$
\text { ce }=\left.\frac{d\left(\frac{w_{r}}{G_{r}}-\frac{w_{s}}{G_{s}}\right)}{d \lambda_{r}}\right|_{\substack{\lambda_{r}=1 / 2 ; \\ G_{r}, G_{s} \text { given in denominator } \\ Y_{r}, Y_{s}{\text { given in } m_{r r}, m_{s r}}}}=\frac{2 w_{r}(1-\phi)}{G_{r}}\left[\frac{(\varepsilon-1)}{P_{r}} \frac{d G_{r}}{d \lambda_{r}}+\frac{(\sigma-\varepsilon)}{G_{r}^{M}} \frac{d G_{r}^{M}}{d \lambda_{r}}\right]
$$

values of the endogenous variables at the symmetric equilibrium $\left(\lambda_{r}=1 / 2\right)$

$$
\begin{array}{ll}
G_{r}^{M}=G_{s}^{M}=\left(\frac{1+\phi}{2}\right)^{\frac{1}{1-\sigma}} ; & \frac{d G_{r}^{M}}{d \lambda_{r}}=\frac{d G_{s}^{M}}{d \lambda_{r}}=-\left(\frac{1-\phi}{\sigma-1}\right)\left(\frac{1+\phi}{2}\right)^{\frac{\sigma}{1-\sigma}} ; \\
G_{r}=G_{s}=\left[1+\left(\frac{1+\phi}{2}\right)^{\frac{1-\varepsilon}{1-\sigma}}\right]^{\frac{1}{1-\varepsilon}} ; & \frac{d G_{r}}{d \lambda_{r}}=\frac{d G_{s}}{d \lambda_{r}}=\left[1+\left(G_{r}^{M}\right)^{1-\varepsilon}\right]^{\frac{\varepsilon}{1-\varepsilon}}\left(G_{r}^{M}\right)^{-\varepsilon} \frac{d G_{r}^{M}}{d \lambda_{r}} \\
w_{r}=w_{s}=\frac{\rho\left[\sigma b_{r}(1+\phi)-\frac{\left(1-\phi^{2}\right)}{2}\right]}{\left(\frac{1}{2-\sigma b_{r}}\right)^{2}-\frac{\phi^{2}}{4}} & b_{r}=b_{s}=\left(\frac{1+\phi}{2}\right)^{\frac{\varepsilon-\sigma}{1-\sigma}}\left(1+\left(\frac{1+\phi}{2}\right)^{\frac{1-\varepsilon}{1-\sigma}}\right)
\end{array}
$$




\section{Appendix C: Determination of the bifurcation pattern}

In this appendix we provide an example of our numerical approach. We first solve numerically for the break points for different values of $\sigma$ and $\varepsilon$. In the two matrices below we increase the value of $\sigma$ in the lines (top to bottom) from 2.5 to 6 in steps of 0.5 . The value of $\varepsilon$ is increased in the columns (left to right) and ranges from 1.5 to 5 , also in steps of 0.5 . The entries in the left matrix are the break points $\phi_{b}(\sigma, \varepsilon)$ for the respective numerical constellation. We focus on the cases below the dotted line where $\sigma \geq \varepsilon$. Notice that the break points are increasing in $\sigma$ and decreasing in $\varepsilon$.

$$
\begin{aligned}
& \longrightarrow \\
& \phi_{b}=\left[\begin{array}{rrrrrrrr}
.280 & .194 & .011 & -0 & 0 & 0 & 0 & 0 \\
.390 & .338 & .261 & .119 & -0 & 0 & 0 & 0 \\
.470 & .434 & .386 & .318 & .206 & -0 & 0 & 0 \\
.532 & .504 & .471 & .427 & .368 & .277 & -0 & 0 \\
.581 & .559 & .533 & .502 & .463 & .412 & .337 & -0 \\
.621 & .602 & .582 & .558 & .530 & .495 & .450 & .388 \\
.653 & .638 & .622 & .603 & .581 & .555 & .523 & .484 \\
.681 & .668 & .654 & .639 & .621 & .601 & .577 & .549
\end{array}\right] \\
& \text { break points } \phi_{b}(\sigma, \varepsilon)
\end{aligned}
$$

$$
\tilde{V}_{(3)}=\left[\begin{array}{ccccccccc}
.765 & -.290 & .017 & -.0 & 0 & 0 & 0 & 0 \\
.417 & .043 & -.091 & .092 & -.0 & 0 & 0 & 0 \\
.203 & .052 & -.003 & -.032 & .047 & -.0 & 0 & 0 \\
.103 & .034 & .011 & -.005 & -.012 & .026 & -.0 & 0 \\
.056 & .021 & .009 & .0023 & -.004 & -.004 & .01 \overline{4} & -.0 \\
.032 & .013 & .007 & .0034 & .0002 & -.002 & -.002 & .009 \\
.019 & .009 & .005 & .0029 & .0012 & -.001 & -.001 & -.004 \\
.012 & .005 & .003 & .0022 & .0013 & .0004 & -.001 & -.006
\end{array}\right] \quad \downarrow
$$

We then use these solutions for the break points to compute the value of $\tilde{V}_{(3)}\left(\sigma, \varepsilon, \phi_{b}(\sigma, \varepsilon)\right)$ for the corresponding parameter constellation. The right matrix reveals that in the admissible parameter range there are both positive values (tomahawk bifurcation) and negative values (pitchfork bifurcation) of $\tilde{V}_{(3)}\left(\sigma, \varepsilon, \phi_{b}(\sigma, \varepsilon)\right)$. Figure 3 is a stylized graphical representation of the matrix on the right hand side.

In the web supplement to this paper (available under http://www.uni-due.de/js) we provide a MATHEMATICA 5.0 routine that computes analogous matrices for arbitrary start and end values of $\sigma$ and $\varepsilon$ and for arbitrarily small interval steps. 